\title{
Household Energy Conservation Intervention: A Game versus Dashboard Comparison
}

\author{
Jan Dirk Fijnheer ${ }^{1-2}$, Herre van Oostendorp ${ }^{1}$ and Remco C. Veltkamp ${ }^{1}$ \\ ${ }^{1}$ Dept. of Information \& Computing Sciences, Utrecht University, \\ Princetonplein 5, 3584 CC Utrecht, NL \\ ${ }^{2}$ Inholland University of Applied Science, Wildenborch 6, 1112 XB Diemen, NL \\ \{J.D.L.Fijnheer, H.vanoostendorp, R.C.Veltkamp\}@uu.nl
}

\begin{abstract}
This paper presents the results of a study, comparing a game versus a dashboard with respect to energy conservation in the household. In a pretestposttest design, an empirical study tested whether change in attitude, knowledge, engagement and behaviour with respect to energy conservation in the household was different for participants playing Powersaver Game compared to a control condition where participants used an energy dashboard with the same content, but excluding game features. The aim of this game (developed using an iterative user-centered game design methodology) is to influence household energy consumption by means of electricity and gas usage in the long-term. The intervention time was at least 5 weeks and pre and post measures were based on 21 days intervals. All energy conservation activities that the application provides (e.g. washing clothes on low temperatures) take place in the real world and feedback is based on real time energy consumption. This real data into the game approach aims to optimize the transfer between the game world and the real world. Energy consumption significantly changed in the game condition compared to the control condition, and the difference between both conditions is more than $33 \%$ after the intervention. In the game condition, knowledge about energy conservation was significantly increased, although no significant differences in increase of attitude and engagement were found. We conclude that Powersaver Game is effective in transfer of energy conservation knowledge, which leads to energy saving behaviour on the long term. However, it cannot be concluded that playing the game leads to a greater change in attitude, probably because attitude scores of the participants were high from the start.
\end{abstract}

Keywords: Gamification, Energy Conservation, User Studies, Persuasive Games, Behaviour Change.

\section{Introduction}

Gamification by incorporation of game features can be a valuable strategy for making nongame products, services, or applications, more motivating, and/or for engaging the user [1]. Therefore, we expect that a persuasive application that aims to stimulate energy conservation is more effective when game features like missions, quizzes, narrative, competition and rewards are implemented. Additionally, besides game features, the inclusion of reality by using inversed gamification principles in a persuasive application can be an outstanding effective means to change people's energy conservation behaviour [2]. 
As presented in Figure 1, in a normal gamification process, game features such as missions, levels, quizzes, narrative, competition, badges and feedback, are implemented in real world processes to stimulate desirable behaviour. In this research project, a different and novel approach is chosen. It takes the opposite approach by implementing real world processes like 50 household energy activities into the game design itself. The aim of this approach is to optimize the transfer between the game world and the real world. When the transfer is optimized, the game is expected to be more effective in change of behaviour and attitude [3]. This inverse gamification approach is in line with the approach of realityenhanced serious games [4]. In both approaches user's real-world activities feed a digital serious game or gamified application. Players are immersed in real-life situations that is generated by user interaction with a virtual environment.

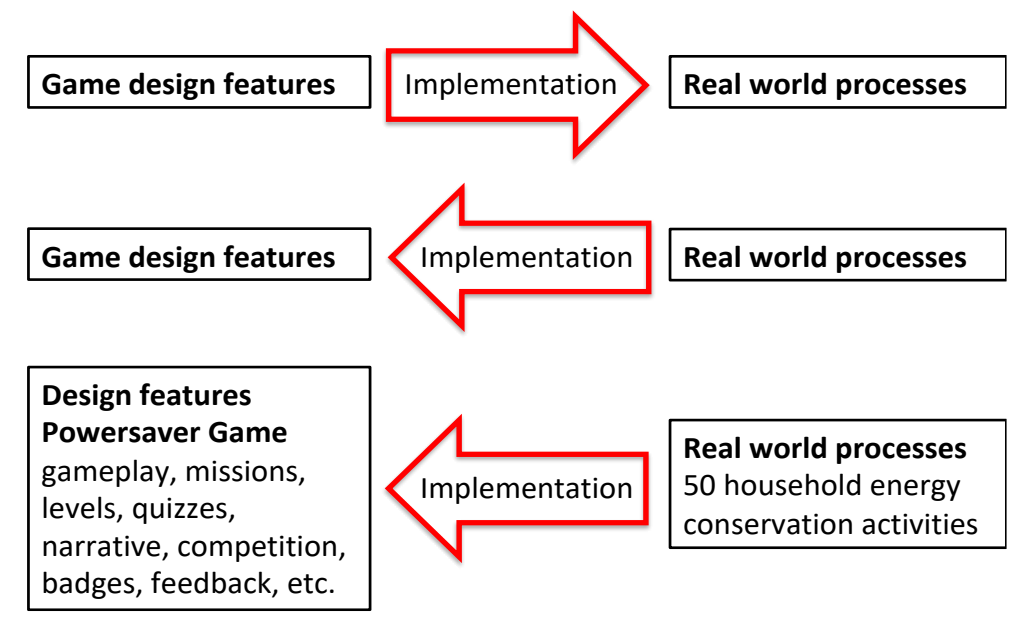

Figure 1. Normal (above) and novel inverse gamification approach (middle and below)

Implementing real world processes in a game design is still an emerging principle in gamification research [2]. When people are highly engaged, they are apt to adopt the attitude that is promoted in the application [5]. This can lead to a higher awareness of relevant factors involved in, for instance, energy conservation. In effect, attitude may positively change, and subsequently trigger a change in energy saving behaviour on the long term. As presented in Figure 2, the assumed chain of events that higher awareness (more accessible knowledge) leads to attitude change, which leads to behaviour change, is what persuasive games try to accomplish $[6 ; 7 ; 8]$.

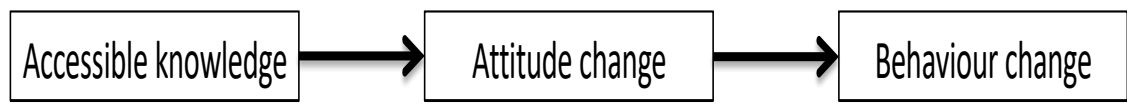

Figure 2. Assumed chain of events in behaviour change

The persuasive application Powersaver Game is developed in an iterative user-centered design approach with specific attention to optimize transfer and evaluation of game features $[2 ; 9]$. Powersaver Game is used as a tool in a larger research project that examines the influence of playing in the real world on attitudes towards energy conservation, and on energy conservation behaviour on the long term. The focus is specifically on energy consumption in households by means of electricity and gas usage. The aim is to contribute to the stimulation of individual sustainable behaviour by studying how gamification can be a positive incentive for people to change their behaviour regarding energy use at home. It also aims to study whether transfer from game play to real life behaviour has a long-term character. It is conducted over a longer period of time, measures changes in knowledge, attitude, engagement and behaviour also after delay, and includes an adequate control 
condition [8]. To attain these aims families have played the Powersaver Game or used in the control condition the Powersaver Energy Dashboard version which contains no game features.

The research question is whether there are changes in knowledge transfer, attitude towards energy conservation, engagement and energy conservation between the game and control condition. This involves, basically, examination of the effectiveness of a game focused on energy conservation. We hypothesize that knowledge, attitude, engagement and energy conservation of participants playing the game will increase more than that of participants in the dashboard control condition.

\subsection{Related Work}

In general the quality of most studies that evaluate the effect of gamification is poor and the reported results are ambiguous [10]. Gamification research regarding to energy conservation of households has shown that the integration of serious games into real life can have positive effects on attitude and behaviour [2]. Searches were performed in scientific databases to select games that had been used as a research instrument with partial similarities to our research. To be selected, a game; 1 - has to raise awareness concerning energy conservation at home, 2- transfers information about energy consumption so that players acquire more knowledge, 3 - influences players to change their behavior concerning energy consumption in real life, 4- integrates behavior in real life into the game by monitoring energy consumption in real life and using this information in the game progression, 5- is played over a relatively long period of time and has several sessions and 6- has a compelling and complex storyline that is able to engage players. Eight games were selected and analyzed. See Table 1.

Table 1. Related work Energy game's

\begin{tabular}{l}
\hline The Power House [11] \\
2 Power Agent $[12 ; 13]$ \\
\hline 3 Power Explorer $[14 ; 15]$ \\
\hline 4 EcoIsland $[16]$ \\
\hline 5 EnergyLife $[17 ; 18]$ \\
6 Power House $[19 ; 20]$ \\
7 Agents Against Power Waste [21] \\
\hline Energy Chickens [22]
\end{tabular}

The empirical effects that are reported, in changing knowledge, behaviour attitude and/or engagement, are positive. We reported on these studies before, see Fijnheer and Van Oostendorp [2]. But unfortunately some studies have general shortcomings such as; the lack of a control condition, the intervention time was short, no real consumption measurements are used, implementation of gamification could be better, limited number of variables is measured and/or the lack of pre-measurements and post-measurements [2; 9]. In our study we have tried to overcome these limitations.

In research on the use of smart meter-related feedback applications to stimulate energy conservation, which have similarities with our control condition, the Powersaver Energy Dashboard, inconsistent outcomes are reported. In a study of Geelen et al. [23] a large sample of Dutch households $(n=519)$ were divided into an intervention group that had an energy dashboard and control group that did not have that. Results show no significant difference in reduction in electricity and gas consumption between both groups over a long period. However, opposite outcomes are reported in a meta-analysis of Karlin and Zinger [24]. This study concludes that applications that provide feedback are most effective for 
pag. 26

promoting energy conservation when they are combined with goal-setting or external incentive interventions. Despite the inconsistent outcomes of these two studies we see the Powersaver Energy Dashboard as an ideal instrument in the control condition, because of the absence of gamification features. This makes it possible to relate different outcomes, in energy conservation between game and dashboard users, to these combined gamification features.

In the next section the research design is presented, with special attention to game design. In the third section the outcomes of the empirical study are discussed. Finally, we draw conclusions and discuss how we will continue our research with Powersaver Game.

\section{Method}

Media comparison research examines differences in learning the same content of a game or as similar as possible - with conventional media, answering the research question: "Do people learn better with games or conventional media [25]?" Inspired by this approach, our focus is comparing a persuasive game (Powersaver Game) and control condition (Powersaver Energy Dashboard) both within a computer-based medium. This prevents us for problems of possible media differences, and possibly will contribute to get more inside in the persuasiveness between both applications [26]. Powersaver Game is a persuasive game where several gamification features are incorporated, and can be expected to stimulate energy conservation. Powersaver Energy Dashboard is a learning application that provides instruction and feedback on energy conservation. In both conditions every 2 days families receive the same information about energy conservation about a specific theme, e.g. washing clothes, and receive feedback. Besides knowledge transfer, i.e. learning results, we also measure attitude, engagement and behaviour, i.e. energy consumption.

\subsection{Participants}

In this study 21 households including 49 participants older than 12 years participated on a voluntary basis in this experiment. 6 Households dropped out during the intervention. The loss is 17 participants. From the remaining 32 participants who finished the application only 15 from 7 households in the game condition filled in all questionnaires.

\subsection{Design}

Powersaver Game is a web-based application and is played in households with involvement of the whole family. The navigation by the player of Powersaver Game is done by point and click in the Internet browser. It is an Eco-feedback, Multiplayer, Roleplaying and Point \& Click Adventure game [27] and has been designed in an iterative process [9]. A real time connection between the household energy meter and game server is accomplished by dataloggers with an Internet connection. The data of energy consumption is sent to a database of a server at Utrecht University.

Avatars of family members are the central characters of Powersaver Game. The family composition in the game is customized to the household (see Figure 3). The game starts with an introduction of the story. A storyline in a game can be engaging because it can stimulate our emotions [28; 29]. A family arrives at a dilapidated country house where a professor had caused a failed experiment (see Figure 4). The family enters the main hall of the house that contains several doors (see Figure 5). Behind each door a room is situated in which a game character in the form of a confused electrical device has been located. A cat (former pet of the professor) called Kyoto guides the family in the game. 


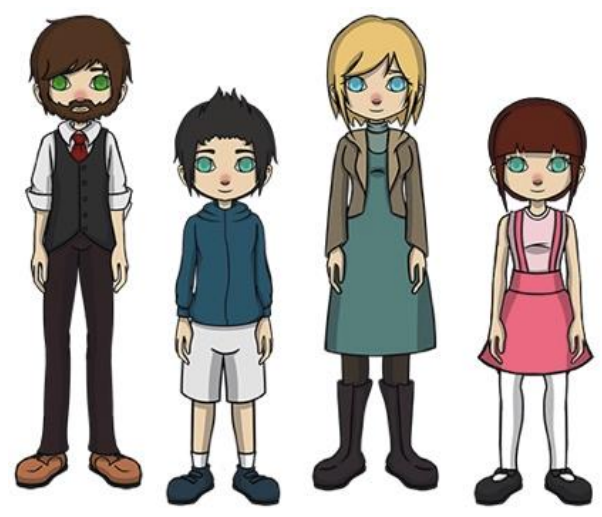

Figure 3. Avatars
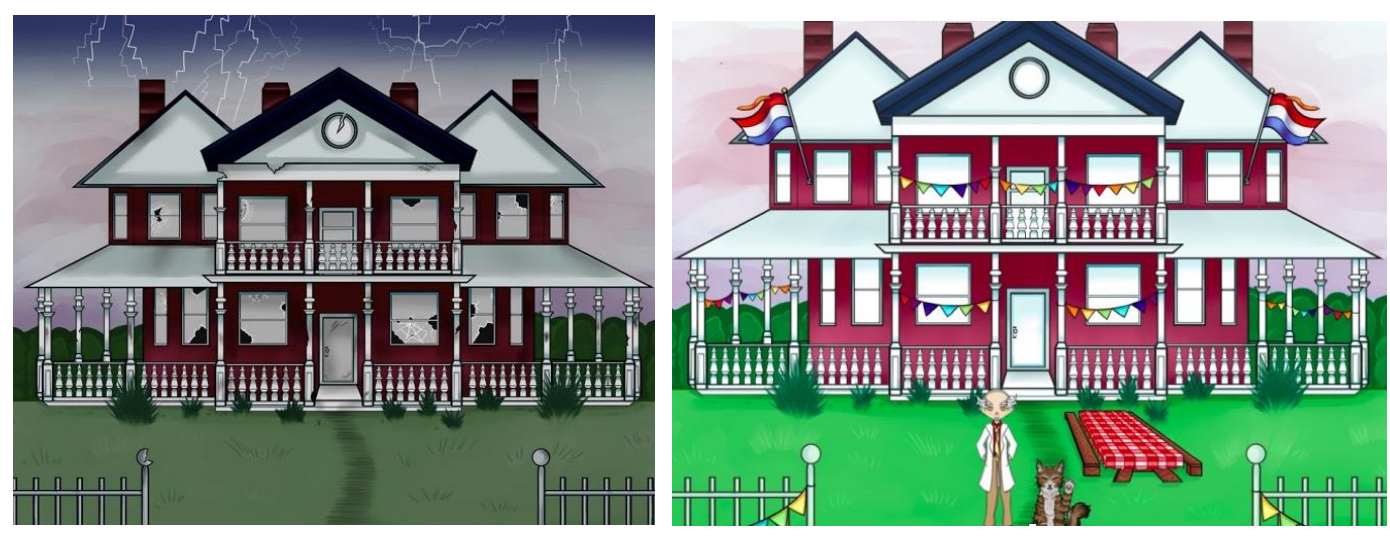

Figure 4. House of the professor; bad begin-state (on the left) and normal end-state (on the right)

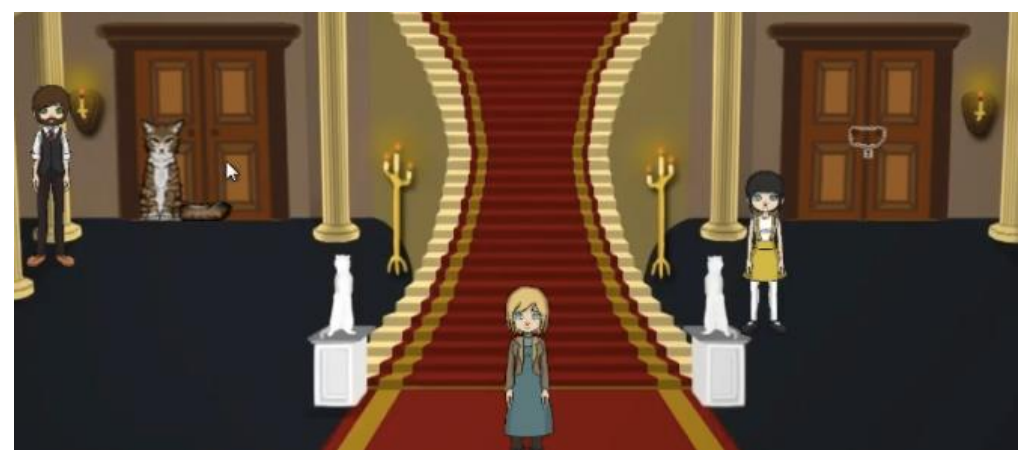

Figure 5. Part of the main hall

In every mission session the family is asked to enter a preselected room. Before the door opens a quiz has to be played. A quiz contains questions about energy conservation that will prepare player's knowledge for the missions that are occurring in that specific room. When the family enters the room a character in the form of a device that is in a confused state is shown (see Figure 6). The family has to accomplish missions, which involve energy conservation knowledge, to help the device to return to a normal state. All missions (e.g. washing clothes on low temperatures) take place in the real world. This represents our inverse gamification principle. The missions are presented in an active writing style, because it is directly related to the urgent situation in the narrative. The total period of playing the game is at least 5 weeks if players end missions and start new ones in the given time. It takes approximately 2 days to complete a mission. The game has 13 missions, 8 
pag. 28

quizzes and an end-battle/scene. The end condition is reached when all devices and the professor are brought out of their confused state (see Figure 4). The player is getting feedback on energy use (see Figure 7) and savings during playing, which is based on average energy consumption in the 21 days before the intervention started. The results of the quizzes are shown and achievement of a completed mission is displayed with a badge (see Figure 8). A household is in competition, another game feature, with 7 virtual households, but assumes to play against real households. Competition is simulated to stimulate households to achieve high scores and it was technically not feasible to implement a real and fair competition.

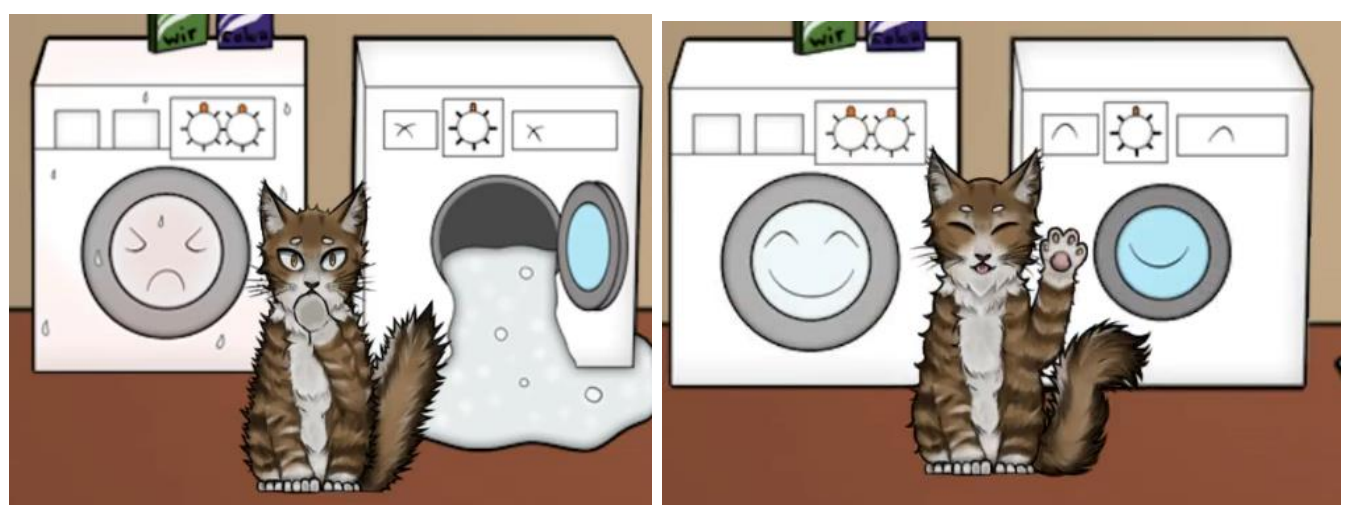

Figure 6. Scenes laundry; bad state (on the left) and normal state (on the right)

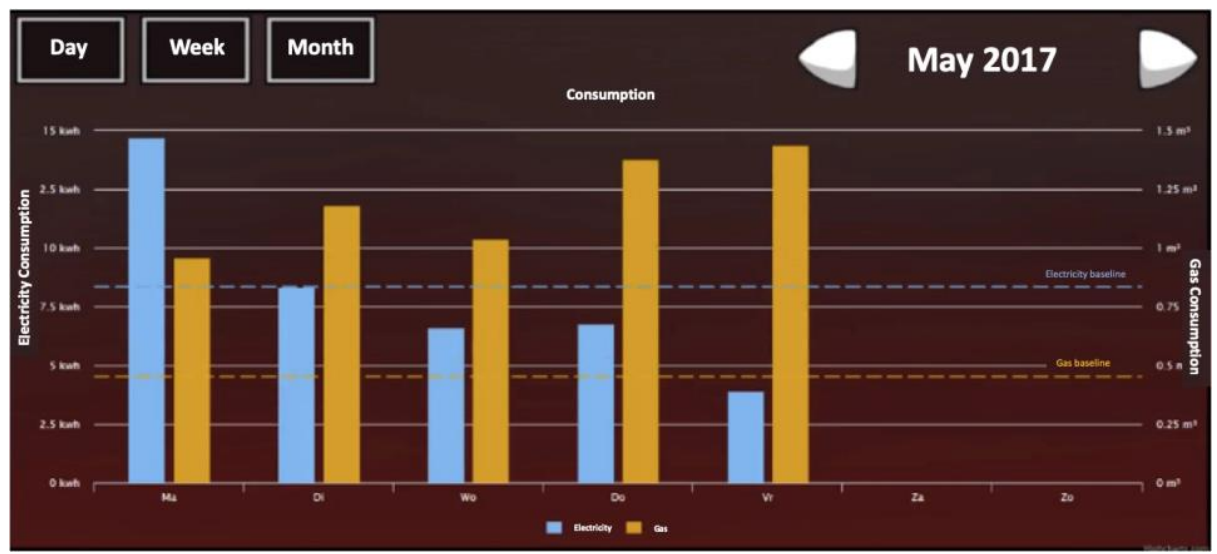

Figure 7. Consumption chart (game and dashboard)

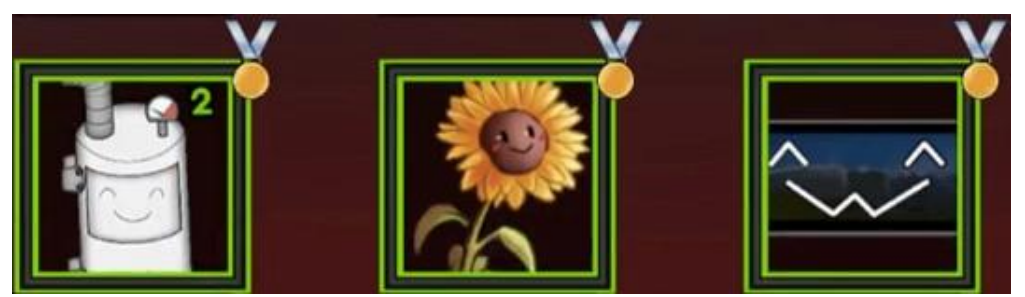

Figure 8. Badges

\subsubsection{Control Condition}

For our approach families used Powersaver Energy Dashboard in the control condition. The energy dashboard has an identical design style as the menu page of the game. As presented in Figure 9, it contains a screen where energy conservation recommendations and 
a timer are presented, and in order to give feedback two screens with energy consumption charts (see Figure 7) and energy conservation results are presented. The form, timing and content of the information the control condition receives are highly similar as in the game condition, but with the exclusion of game features such as missions, quizzes, narrative, competition and rewards [8]. Energy saving activities are presented as tips in Powersaver Energy Dashboard and as missions in Powersaver Game. Energy saving tips in the control condition are formulated in a slightly less active writing style compared to missions in the game condition, because there is no narrative where tips refer to.

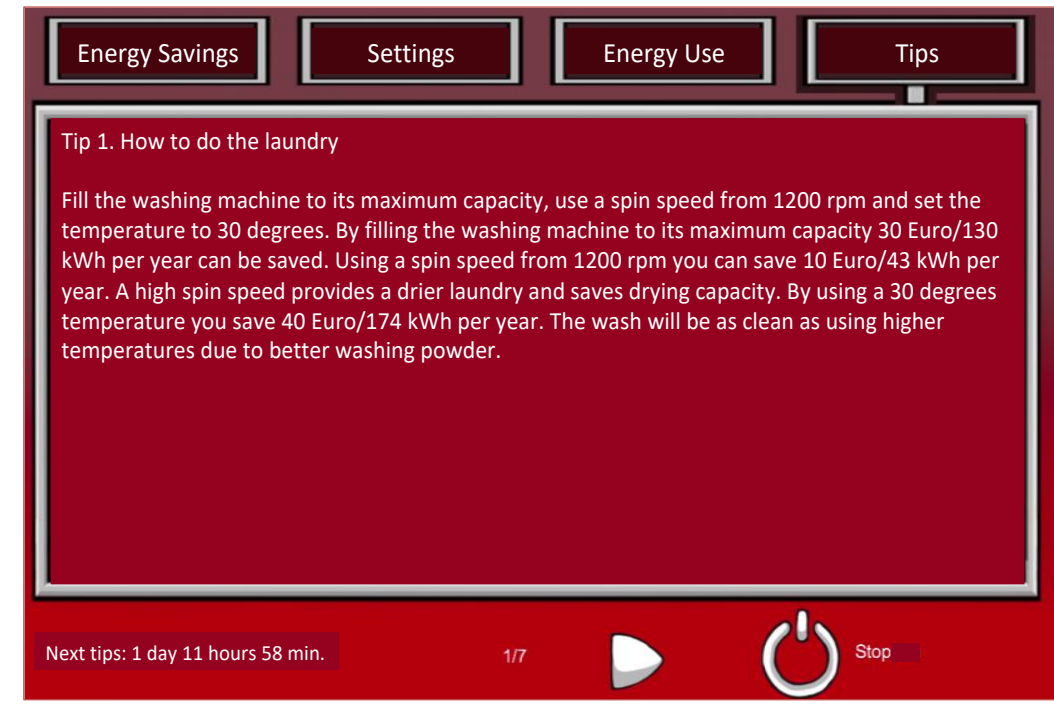

Figure 9. Control condition: Powersaver Energy Dashboard

\subsection{Measurements}

Participants completed an online pretest as well as an online posttest questionnaire to assess their attitude towards sustainable energy consumption related topics and knowledge level towards household energy conservation. For attitude measures both questionnaires included 30 statements rated on a 7 point Likert-scale ranging from strongly disagree to strongly agree. Different statements on the same topics are used in pretest and posttest. 15 Statements are regarding micro-level attitude topics (about sustainable energy consumption in a household) as well as 15 statements regarding macro-level attitude topics (10 statements about sustainable energy and 5 statements about sustainability). Macromeasures were composed partly based on previous research on attitudes toward sustainability [8]. With this approach we measure specific hierarchical attributes of the object of sustainable energy attitude [30]. Krosnick and Petty [31] describe that strengthrelated attributes of attitudes are categorized in affective, cognitive and behaviour intention components. In our questionnaire we only used statements from affective and cognitive categories, because behaviour intention to save energy in the household was already high by voluntary registration to participate in this experiment.

For knowledge measures 12 multiple-choice questions including 4 answer options per question are used. The questions are related to the content about energy conservation from both applications. The same questions are used in the pretest and posttest. Engagement measures were composed based on previous research on engagement in serious games [32]. To monitor engagement participants completed an online questionnaire in the second week and the last week of the intervention. Both questionnaires included the same 7 statements to be rated on a 7 point Likert-scale ranging from strongly disagree to strongly agree.

Behaviour, in the form of energy consumption, is monitored during 21 days before the intervention to set a good baseline of average energy consumption. In both applications the user is getting feedback (on energy use and savings) during the intervention. And after the 
pag. 30

intervention the energy consumption is monitored for 21 days to examine the impact of the intervention.

\subsection{Procedure}

Participants have been recruited using different methods and communication channels like social media, direct mail, digital newsletters and public lectures. Participants registered at the beginning of 2017 using an online form. They could participate when the technical situation of their energy supply (e.g. presence of smart energy meter) was adequate. In spring 2017, 49 participants from 21 households filled in the online pretest. To monitor real energy consumption in this period also hardware was installed in the households. It took at least 21 days of monitoring to set a firm baseline. All participants above 12 years replied to the pretest questionnaire about attitude and knowledge measurements and the first engagement questionnaire in the second week of the intervention. Participants were randomly assigned to conditions, however we took care that there was a global matching between conditions on the composition of the household (adults and children), attitude towards energy conservation (higher or lower than average compared to other participants) and energy consumption (higher or lower than average of the same type of households in The Netherlands). Knowledge scores are not used in this assignment process because all participants scored very low. All household types are equally represented in each condition; 11 households are assigned to the game condition and 10 households are assigned to the control condition. The intervention started in June and ended in July 2017, and over this period energy consumption is measured. Some households ended later due to delay in starting new sessions. From the 11 households that started in the game condition 6 households finished on schedule (on average 5,5 weeks) and 4 households finished later (on average 18 weeks). One household did not finish the game due to personal circumstances. From the 10 households that started in the control condition 5 finished in on average 13 weeks and the other 5 households stopped halfway after 4 weeks. From these 5 households in the control condition that stopped 4 households have children in the adolescence age group. The 5 households that finished in the control condition do not have children in the adolescence age group. When a household finished all the sessions they were asked to fill in the online posttest. Only 15 participants, a third of the total, responded to the second questionnaire about engagement before the last week of the intervention and the posttest questionnaire about attitude and knowledge measurement after the intervention. These 15 participants who responded to all questionnaires are from 7 households in only the game condition. The hardware was disconnected after at least 21 days from the end of the intervention.

\section{Results}

The effects on energy conservation and knowledge, engagement, and attitude measures are presented below. Energy conservation between the game and control condition is based on 6 households from the game condition that have finished on schedule (on average 5,5 weeks) and 5 households from the control condition that have finished (on average 13 weeks). 4 Households that finished the game later (on average 18 weeks) did not provide data on energy consumption within the time constraints for our study. Unfortunately the post-measurements fell in the heating season. In this season Dutch households warm their houses using gas boilers, because the average outside temperature is below 18,5 degree. This causes a large difference in $\mathrm{m}^{3}$ gas consumption between the heating - and non-heating season, so that post- and premeasurements in both seasons cannot be compared.

Only knowledge, engagement, and attitude measures from the game condition are discussed due to lack of sufficient observations in the control condition on the questionnaires. 


\subsection{Energy Conservation measures}

The results in energy conservation, during the total intervention period and during the 21 days post-intervention period, between households in the game and control condition are presented in Table 2. The average energy consumption per day from 21 days after the intervention is compared to the consumption over 21 days before the intervention. The difference in percentage change of total energy consumption $\left(\% \Delta \mathrm{kWh}\right.$ electricity $+\% \Delta \mathrm{m}^{3}$ gas / 2) is presented as well as the percentage change in consumption in $\mathrm{kWh}$ electricity and $\mathrm{m}^{3}$ gas. Because household conservation of both $\mathrm{kWh}$ electricity and $\mathrm{m}^{3}$ gas are related we conducted first a multivariate analysis of variance (MANOVA). There is a significant difference between both game and control condition when considered jointly on the variables conservation of $\mathrm{kWh}$ electricity and $\mathrm{m}^{3}$ gas: At the Intervention, Wilk's $\Lambda=0,17$, $F(2,8)=19,66, p=0,001$, partial $\eta^{2}=0,83$. And at the Post-intervention, Wilk's $\Lambda=0,34$, $F(2,8)=7,82, p=0,01$, partial $\eta^{2}=0,66$. To examine whether the game and control condition had an effect both on $\mathrm{kWh}$ electricity and $\mathrm{m}^{3}$ gas, independent-samples t-tests on the gain scores are performed to test if differences in percentages of change between the game and control condition on each of the energy conservation measures are significant.

Table 2. Energy Conservation: Mean changes, standard deviations, $t$-statistic and significance level of difference.

\begin{tabular}{|c|c|c|c|c|c|c|c|}
\hline Energy & Game & & Control & & Diff & & \\
\hline Conservation & M & SD & $\mathrm{M}$ & $\mathrm{SD}$ & $\mathrm{M}$ & $\mathrm{t}$ & $\mathrm{p}$ \\
\hline \multicolumn{8}{|l|}{ Intervention } \\
\hline Total & $20,9 \%$ & 9,4 & $3,7 \%$ & 15,5 & $17,2 \%$ & $-2,28$ & $<0,05$ \\
\hline kWh Electricity & $16,7 \%$ & 5,6 & $-1,9 \%$ & 3,4 & $18,6 \%$ & $-6,45$ & $<0,05$ \\
\hline $\mathrm{M}^{3}$ Gas & $25 \%$ & 20 & $9,3 \%$ & 29,9 & $15,7 \%$ & $-1,05$ & $\mathrm{~ns}$ \\
\hline \multicolumn{8}{|l|}{ Post-intervention } \\
\hline Total & $21,4 \%$ & 7,7 & $-12,2 \%$ & 18,5 & $33,6 \%$ & $-4,08$ & $<0,05$ \\
\hline kWh Electricity & $12,9 \%$ & 7,9 & $-1,7 \%$ & 16,6 & $14,5 \%$ & $-1,92$ & $<0,05^{*}$ \\
\hline $\mathrm{M}^{3} \mathrm{Gas}$ & $30 \%$ & 12,1 & $-22,7 \%$ & 38,3 & $52,7 \%$ & $-3,21$ & $<0,05$ \\
\hline
\end{tabular}

In the intervention period there is a significant difference of $17,2 \%$ in total change in energy conservation between both conditions: $t(9)=-2,28, p<0,05$ : while the game condition consumes $20,9 \%$ less energy than in the total pre-intervention period of 21 days, the control condition only consumes $3,7 \%$ less energy. When we look specifically at conservation of $\mathrm{kWh}$ electricity there is a significant difference of $18,6 \%$ between groups: $t(9)=-6,45, p<$ 0,05 . The game condition consumes $16,7 \%$ less $\mathrm{kWh}$ electricity than before, while the control condition consumption consume $1,9 \%$ more $\mathrm{kWh}$ electricity. The difference between the groups of $15,7 \% \mathrm{~m}^{3}$ gas consumption is not significant: $t(9)=-1,05, p>0,05$.

In the total 21 days post-intervention period there is a significant major difference of $33,6 \%$ in total change in energy conservation between both conditions: $t(9)=-4,08, p<$ 0,05 : while the game condition consumes $21,4 \%$ less energy than in the total 21 days preintervention period, the control condition consumes $12,2 \%$ more energy. When we look specifically at conservation of $\mathrm{kWh}$ electricity there is a significant difference of $14,5 \%$ between groups: $t(9)=-1,92, p<0,05$ (one-tailed test). The game condition consumes 
pag. 32

almost $13 \%$ less $\mathrm{kWh}$ electricity than before, while the control condition consumption is almost the same as before the intervention. The largest significant difference between the groups is $52,7 \% \mathrm{~m}^{3}$ gas consumption: $t(9)=-3,21, p<0,05$. Notable is that in general the standard deviation of the control condition is high.

\subsection{Knowledge, Engagement and Attitude measures}

The results in knowledge, engagement and attitude measures of participants are presented in Table 3. These fifteen participants who filled out all questionnaires (thirty percent of all participants), as explained above, are only from the game condition. Paired-samples t-tests are executed to conclude whether differences between the pretest and posttest are significant.

Table 3. Knowledge, Engagement and Attitude in the Game Condition: Means, standard deviations, $t$-statistic and significance levels of difference.

\begin{tabular}{|c|c|c|c|c|c|c|c|c|}
\hline & \multicolumn{2}{|c|}{ Pretest } & \multicolumn{2}{|c|}{ Posttest } & \multicolumn{2}{|c|}{ Post - Pre } & \multirow[b]{2}{*}{$\mathrm{t}$} & \multirow[b]{2}{*}{$\mathrm{p}$} \\
\hline & M & SD & M & SD & $\mathrm{M}$ & SD & & \\
\hline Knowledge* & 4,27 & 1,62 & 5,8 & 1,93 & 1,53 & 1,81 & $-3,29$ & $<0,05$ \\
\hline Engagement & 5,35 & 0,94 & 5,29 & 0,75 & $-0,06$ & 0,45 & 0,54 & ns \\
\hline \multicolumn{9}{|l|}{ Attitude } \\
\hline Total & 5,38 & 0,85 & 5,34 & 0,74 & $-0,04$ & 0,4 & 0,39 & ns \\
\hline Micro-level & 5,35 & 0,88 & 5,43 & 0,75 & 0,09 & 0,51 & $-0,66$ & ns \\
\hline Macro-level & 5,41 & 0,92 & 5,25 & 0,81 & $-0,17$ & 0,4 & 1,61 & ns \\
\hline
\end{tabular}

The average score on knowledge increased from 4,27 to 5,8 points. Although the average score in the posttest is not high (the maximum score possible is 12 points), knowledge about energy conservation increased significant: $t(14)=-3,29, p<0,05$.

The engagement is high and constant during the intervention. There is no significance difference in engagement at the beginning and end of the intervention: $t(13)=0,54, p>$ 0,05 .

All attitude scores are already high from the beginning and the intervention did not lead to a significant attitude change: Attitude total: $t(14)=0,39, p>0,05$; Attitude at microlevel: $t(14)=-0,66, p>0,05$; Attitude at macro-level: $t(14)=1,61, p>0.05$.

\subsection{Correlations between measures within the game group}

To explore if the assumed chain of events as expressed in Figure 2 occurs, that more accessible knowledge leads to more attitude change which leads to greater behaviour change, first the correlations of the variables $\Delta$-knowledge, $\Delta$-attitude and $\Delta$-behaviour are examined. Remarkably, there are no significant correlations detected between these variables.

Next a multiple regression analysis is conducted to explore which variables are significant predictors of the most important criterion variable $\Delta$-behaviour in the total 21 days post-intervention period. This technique enables us to examine the relative influence of variables (the predictors) on the criterion variable. Using the enter method, a significant model emerged $(F(3,11)=25,695, p<0,05)$. The adjusted $R$ square $=.841$ and the predictor 
variables with their Beta values are shown in Table 4 . These outcomes indicate that $84 \%$ of the differences in behavior changes are explained by the predictor variables. The Beta coefficients indicate how much a predictor - if significant - contributes to the performance on the criterion variable. $\Delta$-Behaviour during intervention is the most important predictor (explaining $81 \%$ of the differences on $\Delta$-behaviour post-intervention), and attitude the second important one (explaining 7\%). Other variables are not significant ( $\mathrm{p}>.05$ ).

Table 4. Predictor variables (criterion variable $=\Delta$-behaviour at postintervention)

\begin{tabular}{lll}
\hline Predictor variable & Beta & $\mathrm{p}$ \\
\hline$\Delta$-Energy conservation during intervention period & 0,9 & $<0,05$ \\
Attitude pre-intervention & 0,265 & $<0,05$ \\
$\Delta$-Knowledge during intervention period & 0,177 & $\mathrm{~ns}$
\end{tabular}

ns - not significant at 0,05 level

\subsection{User evaluation of Powersaver Game}

The fifteen participants who filled out all questionnaires from the game condition evaluated Powersaver Game by means of 11 statements and one open question where was asked to give suggestions for improvement. The score is on average 5 on a 7 point Likert-scale, and the standard deviation is 1,3. The following suggestions for improvement are given: Automatic (push-)notifications when a session has ended, energy consumption overviews of specific appliances, pre-selection of specific appliances that are relevant to particular households, more specific feedback about energy consumption, shorter mission texts and general game art improvements.

\section{Conclusion and Discussion}

Based on the results of this study we conclude that there are differences in learning the same content of a persuasive energy conservation game, developed by using an iterative usercentered game design methodology, compared to a dashboard control condition. Furthermore, and most importantly, we conclude that energy consumption changed significantly during the intervention and on the long term. A persuasive game that includes reality by using inversed gamification principles is, thus, effective in learning people to save energy in the household and to actually do that for the long term, while an energy dashboard does not change that behaviour at all. Similar studies also presented positive results but had some shortcomings; the lack of a control condition, the intervention time was short, no real consumption measurements are used, implementation of gamification could be better, limited number of variables is measured and/or the lack of premeasurements and post-measurements [2; 9], which altogether could explain that the positive effect on energy conservation in our study is higher than in previous studies.

From the beginning of the intervention, participants in the dashboard control condition had a delay in starting missions (on average 13 weeks to finish while 5 weeks is possible), did not carry out missions (little or no energy conservation) or quit (50\% in 4 weeks). The 5 households in the dashboard control condition that finished the application conserved a little amount of energy during the total intervention period. This was only caused by $\mathrm{m}^{3}$ gas conservation, while there was no $\mathrm{kWh}$ electricity conservation. Remarkably, the $\mathrm{m}^{3}$ gas consumption rose enormously in the post-intervention period. Unfortunately, these participants in the control condition were not motivated to respond to questionnaires, so the resulting number of questionnaires is too small for meaningfully analyzing the data. It is possible that some participants are disappointed in that they are not assigned to the game condition and therefore less motivated. But there are also participants from the control 
pag. 34

condition who stated after the intervention that they did not prefer to be assigned to the game condition.

In the game condition energy consumption (behaviour) changed and knowledge about saving energy at home increased. Also in this condition, despite of the long intervention time, engagement remained high during the whole intervention. This suggests that the game is effective in stimulating participants long term involvement in household energy conservation activities. The earlier mentioned chain of events (Figure 2) does not completely align with these results. Higher awareness (more accessible knowledge) for a longer period leads to increased knowledge, which leads to behaviour change on the long term, but attitude change did not take place. Also there are no significant correlations between these variables found. But if a multiple regression analysis is conducted ' $\Delta$-energy conservation during the intervention' and 'pre-intervention attitude scores' are significant predictor variables for behaviour change on the long term. It is somehow unexpected that ' $\Delta$-knowledge' is not a significant predictor variable. We do not have enough data to interpret this effect, but we might assume that knowledge transfer from the game to participants endures in (routine) behaviour, but not in increased reproducibility of that knowledge at the test. It is expected that the degree of energy conservation during a long intervention time, which is high in the game condition, endures after the intervention and therefore is a strong predictor variable. The attitude scores on micro-level and macro-level are extremely high, both nearly the same and the intervention did not change it. Because of this a ceiling effect regarding attitude could be the case, resulting in no-gain in attitude, but still being a significant predictor for energy conservation on the long term as the multiple regression analyses showed. Krosnick and Petty [31] mention that the more extreme an attitude is, the more an individual likes the object of the attitude, and the more likely it guides behaviour. All participants have a high attitude score, and thus an extreme attitude towards energy conservation, also those in the control condition. It is unexpected that during the intervention period a substantial number of mainly adolescent participants in the control condition dropped out. Future research questionnaires have to be adjusted to study this phenomenon.

The results of this study can have considerable implications for policymakers and companies in the field of smart energy meters. Now in practice only dashboard designs are used to give feedback on energy consumption (e.g. Nest) and our data seem to indicate that these designs are probably not effective on the long term [23;33].

Constraints of this study are that only from participants in the game condition all dependent variables (knowledge, attitude, engagement and behaviour) could be analyzed and that there is not sufficient data to look closely at the control condition. Independent of the preceding, the results also showed that in the control condition no positive change in energy consumption was attained in the long run. Another constraint is the limited number of households participating in this study. This limitation also occurs in related studies [2] and points to the difficulties of this kind of research. It is worthwhile to note that, although the number of households was limited, still significant differences are found. There is a possibility to scale up the number of participants if the smart energy meter can be monitored without additional hardware and a large(r) campaign to recruit households is launched. The results of the evaluation of Powersaver Game are sufficiently positive and modifications to it are not necessary. Although some suggestions will be considered to adopt depending on the amount of effort and budget. Anyway the missions texts will be shortened, and there will be more attention to the feedback-screens in the user manual.

Future research in persuasive game's should focus on the game characteristics that contribute to the game's persuasiveness [26]. To bring the research field on energy reduction games theoretically, but also practically a step further, the next research question would be useful to examine "Which persuasive features of a persuasive game exactly promote lasting changes in knowledge, attitude and behaviour regarding sustainable energy use of households?". For that purpose we will, in a next phase of research, apply a "value added" approach [25]. Here we examine the effects of the persuasive features personal relevance (by means of customized avatars) and social interaction (by means of 
competition) - separately and combined - on participants' knowledge, attitude and behaviour with respect to sustainable energy consumption with Powersaver Game.

\section{References}

[1] S. Deterding, R. Khaled, L. Nacke \& D. Dixon, "Gamification: Toward a Definition". In Proceedings of the CHI 2011, ACM, Vancouver, BC, 2011.

[2] J. D. Fijnheer, H. van Oostendorp, Steps to Design a Household Energy Game, International Journal of Serious Games, Vol. 3, No. 3, 16 p., September 2016. http://dx.doi.org/10.17083/ijsg.v3i3.131

[3] M. Kors, E. van der Spek, \& B. Schouten, "A Foundation for the Persuasive Gameplay Experience". In Proceedings of the $10^{\text {th }}$ Annual Foundations of Digital Games Conference on the Foundations of Digital Games, CA, USA, 2015.

[4] R. Massoud, S. Poslad, F. Bellotti, R. Berta, K. Mehran, A. De Gloria, A Fuzzy Logic Module to Estimate a Driver's Fuel Consumption for Reality-Enhanced Serious Games, International Journal of Serious Games, Vol. 5, No. 4, 18 p., 2018. https://doi.org/10.17083/ijsg.v5i4.266

[5] D. Ruggiero, The Effect of a Persuasive Game on Attitude towards the Homeless, Unpublished thesis, Purdue University, West Lafayette, USA, 2013.

[6] E. Aronson, T. D. Wilson, R. M. Akert, Social Psychology, Pearson, Upper Saddle River, N.J., 2013.

[7] S. Chen, S. Chaiken, "The heuristic-systematic model in its' broader context", In S. Chaiken and Y. Trope (Eds.), Dual Process Theories in Social Psychology, Guilford Press, NY, 1999.

[8] M. Soekarjo, H. van Oostendorp, Measuring Effectiveness of Persuasive Games Using an Informative Control Condition, International Journal of Serious Games, Vol. 2, No. 2, pp. 3756, 2015. https://doi.org/10.17083/ijsg.v2i2.74

[9] J. D. Fijnheer, H. van Oostendorp, \& R. C. Veltkamp, "Gamification in a Prototype Household Energy Game". In T. Connolly and L. Boyle (Eds.), In Proceedings of the 10th European Conference on Game Based Learning, ECGBL 2016, pp. 192-201, ACPI, Paisley, Scotland, 2016.

[10] S. Deterding, S. Björk, L. E. Nacke, D. Dixon, \& E. Lawley, "Designing gamification: Creating gameful and playful experiences". In Proceedings of the CHI 2013 Extended Abstracts on Human Factors in Computing Systems, 3263-3266, ACM, NY, 2013. https://doi.org/10.1145/2468356.2479662

[11]M. Bang, C. Torstensson, C. Katzeff, "The PowerHouse: A Persuasive Computer Game Designed to Raise Awareness of Domestic Energy Consumption”, In W. Ijsselsteijn, Y. A. W. de Kort, C. Midden, B. Eggen, E. van den Hoven (Eds.), In Proceedings of the Persuasive 2006, Lecture Notes in Computer Science, Vol. 3962, Springer-Verlag Berlin, Heidelberg, pp. 123132, 2006. https://doi.org/10.1007/11755494_33

[12]M. Bang, A. Gustafsson, C. Katzeff, "Promoting New Patterns in Household Energy Consumption with Pervasive Learning Games", In Y. de Kort, W. IJsselsteijn, C. Midden, B. Eggen, B. J. Fogg (Eds.), In Proceedings of the Persuasive 2007, Lecture Notes in Computer Science, Vol. 4744, pp. 55-63. Springer-Verlag, Berlin, Heidelberg, 2007. https://doi.org/10.1007/978-3-540-77006-0_7

[13] A. Gustafsson, C. Katzeff, M. Bang, Evaluation of a Pervasive Game for Domestic Energy Engagement among Teenagers, ACM Comput. in Entertainment, Vol. 7, No. 4, 19 p., 2009. http://doi.acm.org/10.1145/1658866.1658873

[14] M. Bang, M. Svahn, \& A. Gustafsson, "Persuasive design of a mobile energy conservation game with direct feedback and social cues". In Proceedings of the DiGRA 2009 International Conference: Breaking New Ground: Innovation in Games, Play, Practice and Theory, London, UK, 2009.

[15] A. Gustafsson, M. Bang, \& M. Svahn, "Power Explorer - a casual game style for encouraging long term behaviour change among teenagers". In Proceedings of the International Conference on Advances in Computer Entertainment Technology, ACM, NY, pp. 182-189, 2009. https://doi.org/10.1145/1690388.1690419

[16] H. Kimura, T. Nakajima, Designing Persuasive Applications to Motivate Sustainable Behavior in Collectivist Cultures, PsychNology Journal, Vol. 9, No. 1, pp. 7-28, 2011.

[17] L. Gamberini, G. Jacucci, A. Spagnolli, N. Corradi, L. Zamboni, M. Perotti, C. Cadenazzi, S. Mandressi, G. Tusa, C. Björkskog, M. Salo, \& P. Aman, "Saving is Fun: Designing a Persuasive 
Game for Power Conservation". In Proceedings of the 8th International Conference on Advances in Computer Entertainment Technology, ACE 2011, ACM, NY, 2011. https://doi.org/10.1145/2071423.2071443

[18] L. Gamberini, A. Spagnolli, N. Corradi, G. Jacucci, G. Tusa, T. Mikkola, L. Zamboni \& E. Hoggan, "Tailoring Feedback to Users' Actions in a Persuasive Game for Household Electricity Conservation". In Proceedings of the Persuasive Technology: design for Health and Safety, Vol. 7284, pp. 100-111, Springer-Verlag, Berlin, Heidelberg, 2012. https://doi.org/10.1007/978-3642-31037-9_9

[19]B. Reeves, J. J. Cummings, \& D. Anderson, "Leveraging the engagement of games to change energy behavior". In Proceedings of the CHI 2011, ACM, Vancouver, BC, 2011. https://doi.org/10.1109/CTS.2012.6261074

[20] B. Reeves, J. J. Cummings, J. K. Scarborough, L. Yeykelis, Increasing Energy Efficiency with Entertainment Media: An Experimental and Field Test of the Influence of a Social Game on Performance of Energy Behaviors, Environment and Behavior, Vol. 47, Nr. 1, pp. 102-115, 2013. https://doi.org/10.1177/0013916513506442

[21]M. Svahn, Persuasive Pervasive Games: the Case of Impacting Energy Consumption, Dissertation, Stockholm School of Economics, Stockholm, Sweden, 2014.

[22] B. Orlanda, N. Ramb, D. Langc, K. Houserd, N. Klinge, M. Coccia, Saving energy in an office environment: A serious game intervention, Energy and Buildings, Vol. 74, pp. 43-52, 2014. https://doi.org/10.1016/j.enbuild.2014.01.036

[23]D. Geelen, R. Mugge, S. Silvester, The use of apps to promote energy saving: a study of smart meter-related feedback in the Netherlands. Energy Efficiency, Vol. 12, No. 6, pp. 1635-1660, Springer, The Netherlands, 2019. https://doi.org/10.1007/s12053-019-09777-z

[24]B. Karlin, J. F. Zinger, R. Ford, The effects of feedback on energy conservation: A metaanalysis. Psychological Bulletin, Vol. 141, No. 6, pp. 1205-1227, 2015. http://dx.doi.org/10.1037/a0039650

[25] R. E. Mayer, "Multimedia learning and games", In S. Tobias and J. D. Fletcher (Eds.), Computer games and instruction, pp. 281-305. Information Age Publishing, Charlotte, NC, US, 2011.

[26] J. van 't Riet, A. C. Meeuwes, L. van der Voorden, J. Jansz, Investigating the Effects of a Persuasive Digital Game on Immersion, Identification, and Willingness to Help, Basic and Applied Social Psychology, Vol. 40, No. 4, pp. 180-194, 2018. https://doi.org/10.1080/01973533.2018.1459301

[27]E. Adams, Fundamentals of Game Design, 3rd edition, Pearson Education, Peachpit, CA, US, 2014.

[28] M. D. Dickey, Murder on Grimm Isle: The impact of game narrative design in an educational game-based learning environment, British Journal of Educational Technology, Vol. 42, No. 3, pp. 456-469, 2011. https://doi.org/10.1111/j.1467-8535.2009.01032.x

[29]E. F. Schneider, M. Lang, M. Shin, S. D. Bradley, Death with a story how story impacts emotional, motivational, and physiological responses to first- person shooter video games, Human Communication Research, Vol. 30, Nr. 3, pp. 361-375, 2004. https://doi.org/10.1111/j.1468-2958.2004.tb00736.x

[30] S. E. Watt, G. R. Maio, G. Haddock, B. T. Johnson, "Attitude Functions in Persuasion: Matching, Involvement, Self-Affirmation, and Hierarchy”, In W. D. Crano and R. Prislin (Eds.), Attitudes and Attitude Change, pp.189-211. Psychology Press, NY, 2008.

[31] J. A. Krosnick, R. E. Petty, “Attitude strength: An overview”, In R. E. Petty and J. A. Krosnick (Eds.), Attitude strength: Antecedents and consequences. 24 p., Erlbaum, Mahwah, NJ, 1995.

[32]E. D. van der Spek, "Experiments in serious game design: A cognitive approach", Dissertation, Utrecht University, Utrecht, The Netherlands, 2011.

[33] T. Hargreaves, M. Nye, J. Burgess, Making energy visible: a qualitative field study of how householders interact with feedback from smart energy monitors, Energy Policy, Vol. 38, No. 10, pp. 6111-6119, 2010. https://doi.org/10.1016/j.enpol.2010.05.068 